\title{
Efficacy of Glyceryl trinitrate (GTN) to facilitate the rewarming process during cardiopulmonary bypass
}

\author{
Darren Mullane* Di Martin Lenihan, Ciara Hanley, Tom Wall, Irmina Bukowska, Michael Griffin and Georgina Flood
}

\begin{abstract}
Background: Does Glyceryl trinitrate (GTN) administered during rewarming on cardiopulmonary bypass (CPB) impact: time to completion of rewarming prior to separation from CPB circuit, early post-op patient peripheral core temperature gradient, time to maintenance of normothermia (core temperature $>36.5^{\circ} \mathrm{C}$ ) for minimum of $2 \mathrm{~h}$ in the initial post-op period, and plasma lactate concentrations initially post-CPB.

Methods: Single centre prospective randomized trial conducted in the Mater Misericordiae University teaching hospital in Dublin Ireland. Trial registration: ISRCTN registry, ISRCTN10480871, registered 16th of August 2017. 82 patients enrolled. Patients randomised to low dose GTN infusion (0.01 mcg/ $/ \mathrm{kg} / \mathrm{min}$ ) or higher dose GTN infusion $(0.5 \mathrm{mcg} / \mathrm{kg} / \mathrm{min})$ during rewarming on CPB.
\end{abstract}

Measurements and Main results: There was no significant difference between the treatment arms for the total time to being rewarmed, $U=759.0, p=0.84$. There were also no differences between the treatment arms for the time to achieve core temperature greater than 36.5 after two hours, $U=714.0, p=0.52$, the time to achieve plateau core skin temperature, $U=688.0, p=0.37$, and the post-intervention protamine lactate, $U=721.0, p=0.56$.

Conclusions: Higher dose GTN infusion during rewarming on CPB does not improve peripheral-core temperature gradient post operatively and has no effect on post-operative lactate concentrations.

Keywords: Glyceryl trinitrate, Cardiopulmonary bypass, Rewarming, Temperature gradient, Lactate

\section{Introduction}

Cardiopulmonary bypass (CPB) has been the cornerstone for the evolution of cardiac surgery with its first regular use dating back to the 1950's [1, 2]. The CPB machine facilitates surgery, allowing a still and bloodless field, whilst maintaining appropriate cardiac output, blood pressure and pulmonary functions, albeit not without its associated complications [3-5].

$\mathrm{CPB}$ results in vasoconstriction \& reduction in blood flow to the peripheries which is further exacerbated by cooling $[6,7]$. If rewarming back to normothermia is not

\footnotetext{
* Correspondence: mullanedp@gmail.com

Mater Misercordiae University Hospital Division of Anesthesia, 7 Eccles Street, Dublin, Ireland
}

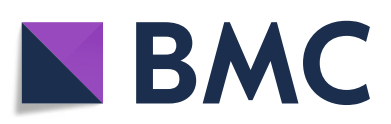

(c) The Author(s). 2020 Open Access This article is licensed under a Creative Commons Attribution 4.0 International License, which permits use, sharing, adaptation, distribution and reproduction in any medium or format, as long as you give appropriate credit to the original author(s) and the source, provide a link to the Creative Commons licence, and indicate if changes were made. The images or other third party material in this article are included in the article's Creative Commons licence, unless indicated otherwise in a credit line to the material. If material is not included in the article's Creative Commons licence and your intended use is not permitted by statutory regulation or exceeds the permitted use, you will need to obtain permission directly from the copyright holder. To view a copy of this licence, visit http://creativecommons.org/licenses/by/4.0/ The Creative Commons Public Domain Dedication waiver (http://creativecommons.org/publicdomain/zero/1.0/) applies to the data made available in this article, unless otherwise stated in a credit line to the data. hypothermia is seen with an increase in lactate levels following separation from the CPB circuit $[8,9]$.

Pharmacological vasodilation during rewarming is one way to counteract the potential deleterious effects of tissue hypoxia and impaired glucose metabolism, which occur as a result of peripheral vasoconstriction.

Deakin et al. showed that sodium nitroprusside during rewarming whilst on $\mathrm{CPB}$, helped reduce the afterdrop phenomenon post operatively in the intensive care unit (ICU) [10]. Notably, time to extubation was also significantly reduced in this cohort of patients who received vasodilator therapy on rewarming. Glyceryl trinitrate $(\mathrm{GTN})$ is another vasodilatory drug that has been used 
Table 1 Comparison of GTN Treatment Arms of Primary and Secondary Outcomes

\begin{tabular}{llll}
\hline Outcome & Low GTN & High GTN & $p$-value \\
\hline Total time to rewarming (minutes) & $33.0(23.0)$ & $35.5(19.0)$ & 0.84 \\
Time to achieve core temperature greater than 36.5 after two hours (minutes) & $240.0(240.0)$ & $300.0(210.0)$ & 0.52 \\
Time to achieve plateau core skin temperature (minutes) & $480.0(240.0)$ & $450.0(438.0)$ & $3.2(2.7)$ \\
Post-intervention Protamine Lactate (mmol/l) & $2.8(1.4)$ & 0.37 \\
\hline
\end{tabular}

Note: values are median (interquartile range)

in the medical setting for over 100 years, for the cardiovascular benefits of coronary artery vasodilation and blood pressure optimization both in an outpatient and intra-operative setting $[11,12]$. Ying-Hsuan Tai's retrospective study in 2016, highlighted the benefit of GTN in attenuating the hyperglycemic response to cardiac surgery, whilst also ameliorating lactate levels in the intensive care setting [13]. GTN administration during rewarming, however, did not improve time to extubation, ICU length of stay, or hospital length of stay.

In our institution to date, we have been using GTN during rewarming on $\mathrm{CPB}$ but have found our exact dosing protocol to be quite variable. We therefore performed a small prospective observational study of GTN use during rewarming in our hospital in 2016. This showed evidence that an infusion at $0.5 \mathrm{mcg} / \mathrm{kg} / \mathrm{min}$ caused a slower rewarming process, but a more sustained normothermia post-operatively, with lower lactate levels in the initial post-operative period when compared to those with no infusion. On an extensive literature review however, we did not find any prospective large trials that assessed the efficacy of a higher dose GTN infusion when compared to a lower dose infusion during rewarming. The authors hypothesized that a higher dose GTN infusion during rewarming, would ameliorate temperature gradients and lactate levels in the acute post-operative period when compared to the significantly lower comparison.

\section{Methods}

This single center prospective randomized trial was conducted in the Mater Misericordiae University Hospital Dublin from January 2017-December 2018. Our study was approved by the Mater Hospital Research \& Ethics Committee (Ref 1/378/1869) and the trial was registered with the ISRCTN registry: ISRCTN10480871, EudraCT Number 2017-002785-44. Registered retrospectively.

All adult patients with capacity to consent undergoing cardiac surgery necessitating CPB were recruited for this trial. Exclusion criteria included age $<18$ years old, allergy to GTN, cardiac surgery requiring deep hypothermic circulatory arrest, cardiac surgery not involving CPB (e.g. offpump cardiopulmonary bypass grafting), lack of capacity to consent, and use of total intravenous anesthesia (TIVA) whilst on CPB. TIVA with propofol was excluded due to its potential beneficial vasodilating properties during $\mathrm{CPB}$ [14]. Based on our previous study we calculated our sample size to need over 59 patients to have a power value of $90 \%$ [15]. 82 patients were enrolled in total to allow for patient dropout.

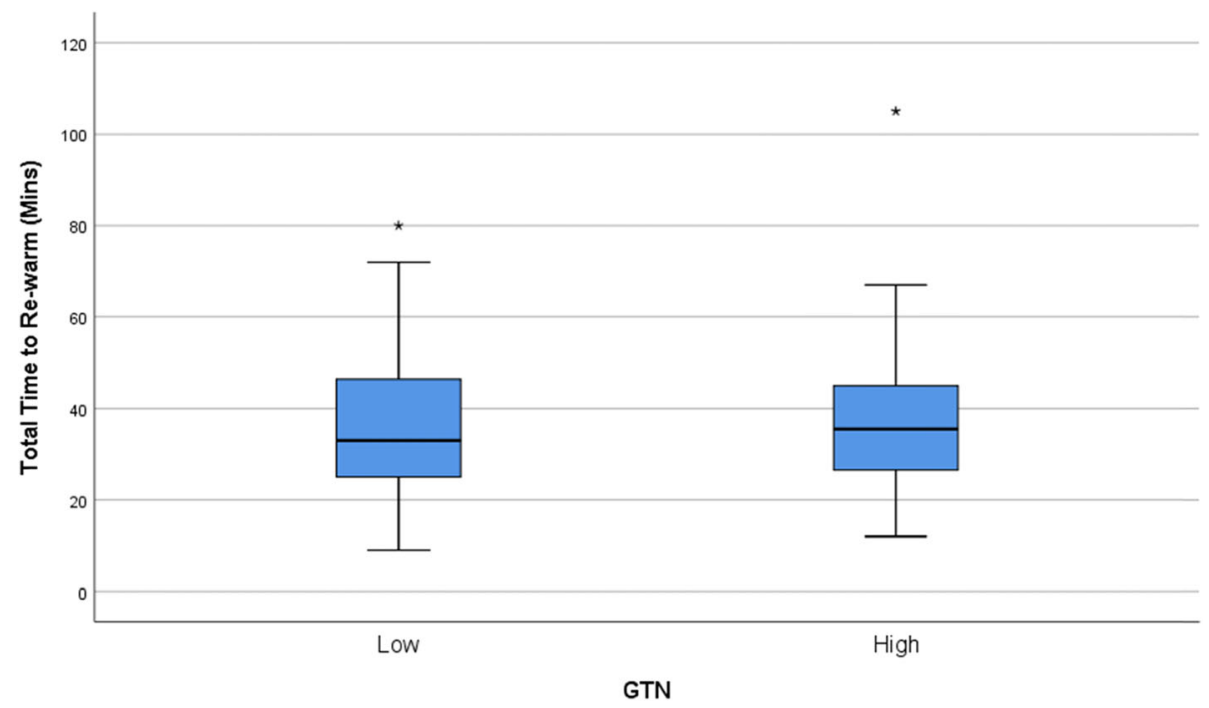

Fig. 1 Box-plot for Total Time to Re-warm 


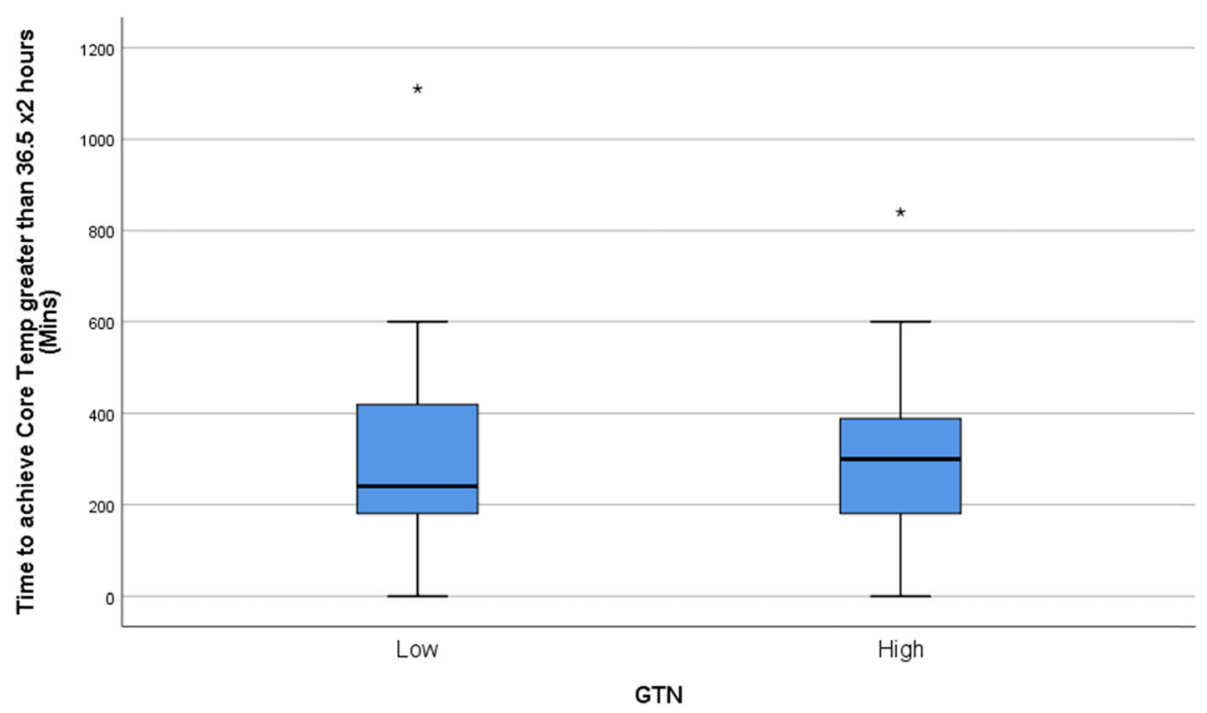

Fig. 2 Box-plot for Time to Achieve Core Temperature Greater Than $36.5 \times 2$ Hours

The primary outcomes that we analyzed evaluated: if GTN administered during rewarming on $\mathrm{CPB}$ impacted (1) time to completion of rewarming prior to separation from CPB circuit, (2) early post-op patient peripheralcore temperature gradient, (3) time to maintenance of normothermia (core temperature $>36.5^{\circ} \mathrm{C}$ ) for minimum of $2 \mathrm{~h}$ in the initial post-op period (and including skin temperature reaching a plateau), and (4) plasma lactate concentrations initially post CPB.

Once written consent for the study was obtained by one of the trial authors, each study subject was randomized via a computer randomization programme to either a low or high dose GTN infusion rate during rewarming on $\mathrm{CPB}$. The primary anaesthesiologist for each case was informed on which GTN dosing protocol to use on rewarming.

\section{Pre-operative assessment}

Baseline demographics recorded included patient age at surgery, patient height, weight \& Body Mass Index (BMI), planned surgery, left ventricular ejection fraction, Euroscore 2, patient co-morbidities \& use of a vasodilator preoperatively. Operating room temperature \& patient temperature pre-operatively were also recorded.

\section{Intra operative assessment}

Standard ASA (American Society of Anesthesiologists) monitoring at induction was used including: temperature

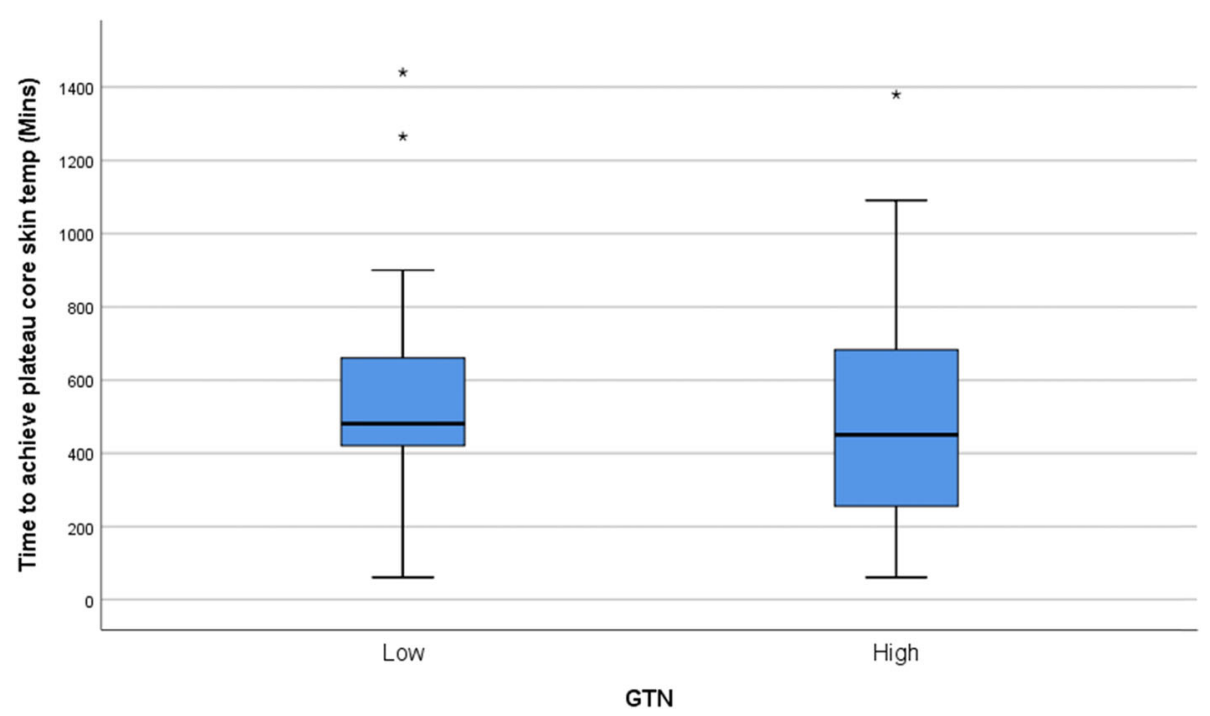

Fig. 3 Box-plot for Time to Achieve Plateau Core Skin Temperature 
measurement with core (bladder), peripheral (nasopharyngeal), \& skin (temporal) monitors, invasive blood pressure measurement via an invasive arterial cannula, arterial blood gas monitoring (ABG) (standard measurements pre and post-CPB), invasive central venous pressure (CVP) monitoring, continuous end tidal carbon dioxide and inhalational anesthetic gas measurement, and transesophageal monitoring if indicated by procedure. Induction was at the discretion of the anaesthetizing consultant which included fentanyl, propofol, midazolam and an aminosteroidal muscle relaxant. Maintenance of anesthesia was conducted with a combination of volatile anesthetic and a fentanyl infusion.

\section{Commencement of CPB}

Anesthesia was maintained by volatile anesthetic (sevoflurane) at $1.5 \%$ into the $\mathrm{CPB}$ circuit for both patient groups. Benzodiazepine and paralysis administration were at the discretion of the consultant anesthesiologist. Heparin dosing was used to keep ACT (activated clotting time) $>450 \mathrm{~s}$. Mean arterial pressure (MAP) was maintained at a MAP of $60-80 \mathrm{mmHg}$ with the aid of metaraminol and sevoflurane, with pump flow rates of 2.2 to $2.8 \mathrm{l} / \mathrm{min} / \mathrm{m} 2$. Mild hypothermia was induced with cooling to 34 degrees as per surgical protocol. ABG monitoring was achieved every $30 \mathrm{~min}$ as per standard monitoring.

\section{Intervention}

At initiation of rewarming, the patient received either: (A) High dose infusion: GTN infusion rate at $0.5 \mathrm{mcg} /$ $\mathrm{kg} / \mathrm{min}$ via CVP line or (B) Low dose infusion: GTN infusion rate at $0.01 \mathrm{mcg} / \mathrm{kg} / \mathrm{min}$ via CVP line. Once core temperature and peripheral temperatures were $>36^{\circ} \mathrm{C}$ and patient was ready for separation from $\mathrm{CPB}$ circuit, GTN infusion rate was set according to preference of the anesthesiologist and based on patient hemodynamics and co-morbidities. Recorded measurements included time taken for completion of rewarming process (both core and peripheral temperatures $>36^{\circ} \mathrm{C}$ ), total dose of GTN infusion (low or high rate), patient temperatures at commencement of $\mathrm{CPB}$ including core (bladder), peripheral (nasopharyngeal) \& skin, lowest temperatures on $\mathrm{CPB}$, and temperatures prior to separation from $\mathrm{CPB}$.

\section{Post-operatively}

Infusions of all vasoactive drugs were set according to clinical need and at the discretion of the anesthesiologist and / or intensivist as indicated for hemodynamic control.

Data recorded included doses of all bolus drugs administered, total doses of all drug infusions administered at application of dressings, dose of GTN administered during rewarming, total dose of metaraminol administered on $\mathrm{CPB}$, and total dose of GTN administered in ICU in first $24 \mathrm{~h}$ post-operatively. Total Bypass time, cross clamp time \& total surgical time were also recorded.

Temperature measurements post-operatively included temperature on application of surgical dressing (signifies end of surgery), ICU room temperature at arrival, hourly temperatures in ICU and lowest temperature recorded in ICU prior to extubation.

Lactate concentrations recorded perioperatively included: baseline $A B G$ in OR, post-protamine ABG, initial ABG on arrival in ICU, and hourly ABG's for the 1st $6 \mathrm{~h}$ in ICU. Lastly, time to extubation was also recorded for both groups.

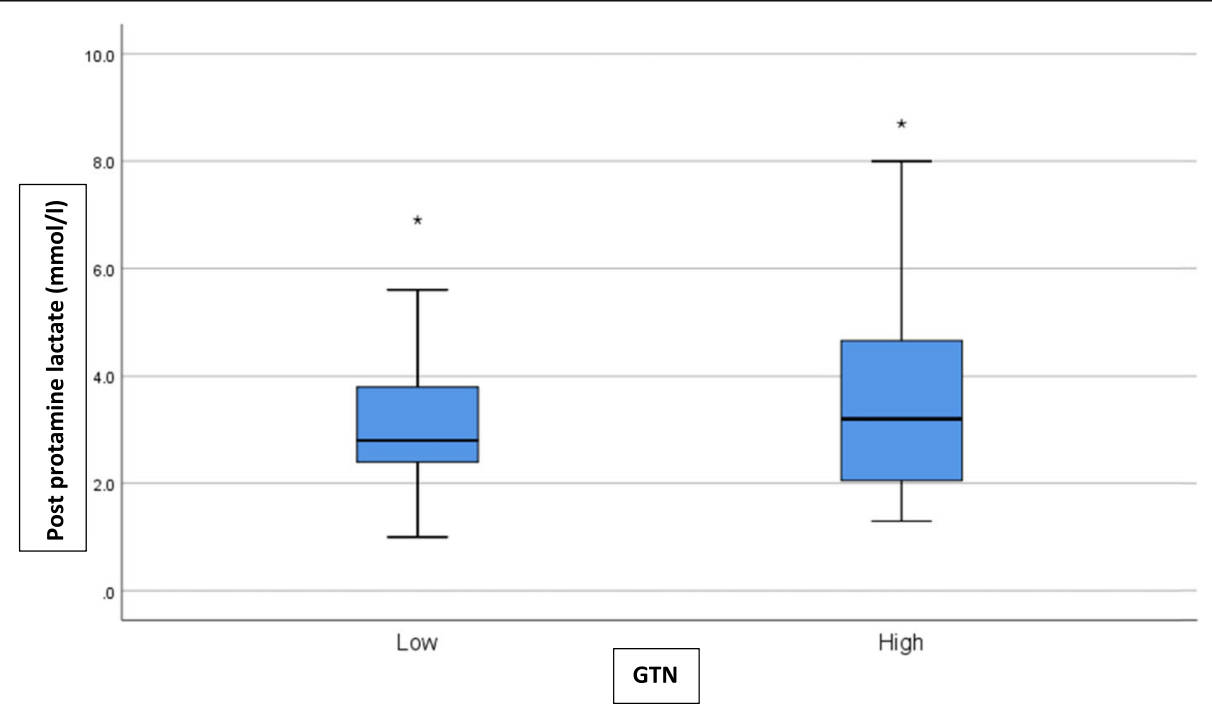

Fig. 4 Box-plot for Post-Protamine Lactate 


\section{Statistical analysis}

The statistical analysis was conducted using an "intention-totreat" approach. The statistical assumption of normality for continuous distributions was assessed using KolmogorovSmirnov tests. Non-parametric Mann-Whitney U tests were performed to compare the treatment arms (Low GTN vs. High GTN) on the primary and secondary outcomes. Medians and interquartile ranges were reported and interpreted for each non-parametric comparison. Statistical significance was assumed at an alpha value of 0.05 and all statistical analyses were performed using SPSS Version 25 (Armonk, NY: IBM Corp.)

\section{Results}

Kolmogorov-Smirnov tests found that all continuous outcome distributions violated the statistical assumption of normality. Non-parametric Mann-Whitney U tests were used for treatment arm comparisons of each outcome of interest. Medians and interquartile ranges for the non-parametric comparisons are presented in Table 1 and depicted visually using box-plots in Figs. 1, 2, 3, and 4. Figure 5 outlines the allocation and randomisation of patients during the study in the CONSORT flow diagram format [16]. There was no significant difference between the treatment arms for the total time to being rewarmed, $\mathrm{U}=759.0, p=0.84$ as presented in Table 1 and depicted in Fig. 1. Table 1 also highlights that there were no differences between the treatment arms for the time to achieve core temperature greater than 36.5 after two hours, $\mathrm{U}=714.0, p=0.52$, the time to achieve plateau core skin temperature, $\mathrm{U}=688.0, p=0.37$, and the postintervention protamine lactate, $\mathrm{U}=721.0, p=0.56$.
Table 2 highlights the differences between both research groups. Mean age was 61.5 years in both groups. There was no significant difference observed in Euroscore 2 scores, BMI, total bypass time, total cross clamp time, and duration of surgery.

\section{Discussion}

This prospective study is the first research trial to evaluate a higher dose GTN infusion vs lower dose GTN infusion during rewarming, to ameliorate the deleterious effects of CPB in Cardiac Surgery. We recruited over 80 patients to have our study adequately powered, but we found no statistically significant differences between any of our primary endpoints when comparing both dosing protocols. Time to achieve plateau temperature between core and skin was equal in both groups, as was time to achieve core temperature $>36.5$. This may account for the lack of statistically significant differences between the initial post-operative lactates. There was also no statistical difference found between the hourly postoperative lactates with either group in the ICU setting, despite the well know association of prolonged $\mathrm{CPB}$ time with elevated lactates post operatively [17-22]. Baseline demographic data, total $\mathrm{CPB}$ time, total time to rewarm \& total surgery time were comparable between both groups including Euroscore 2. This may also explain the comparable time to extubation found between both groups in the setting of a matching post-operative lactate trend. Our results did not replicate the previous positive findings from our earlier study or Ying-Hsuans retrospective review $[14,15]$.

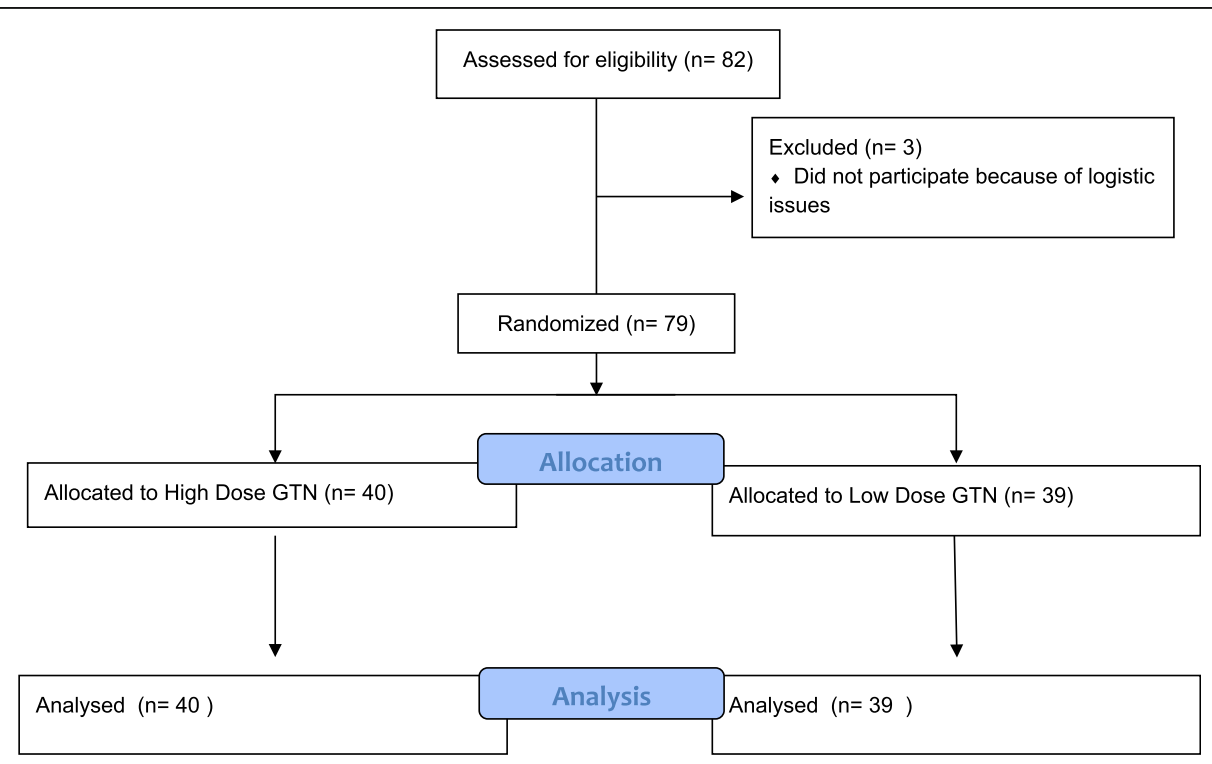

Fig. 5 CONSORT flow diagram reflecting recruitment of patients [23] 
Table 2 Differences Between GTN Groups

\begin{tabular}{|c|c|c|c|}
\hline Variable & Low GTN & High GTN & $p$-value \\
\hline $\mathrm{Age}^{*}$ & $61.5(11.9)$ & $61.5(6.96)$ & 0.99 \\
\hline $\mathrm{BMI}^{*}$ & $28.8(4.9)$ & $28.4(4.9)$ & 0.77 \\
\hline Cross Clamp Time (mins)* & $102.9(32.1)$ & $100.4(32.0)$ & 0.73 \\
\hline Euroscore $2^{* *}$ & $1.6(1.0)$ & $1.8(2.0)$ & 0.72 \\
\hline Total Bypass Time (mins) ${ }^{* *}$ & $130.0(61.0)$ & $123.5(47.0)$ & 0.64 \\
\hline Total Time to Re-warm (mins)** & $33.0(23.0)$ & $35.5(19.0)$ & 0.84 \\
\hline Total Dose of GTN During Re-warming (mcg) & $25.0(25.0)$ & $1506.0(856.0)$ & $<0.001$ \\
\hline Duration of Surgery (mins) $)^{* *}$ & $312.0(120.0)$ & $315.5(65.0)$ & 0.40 \\
\hline Time to Extubation (mins)** & $900.0(400.0)$ & $900.0(360.0)$ & 0.99 \\
\hline ICU Arrival Lactate $(\mathrm{mmol} / \mathrm{l})^{* *}$ & $2.3(1.9)$ & $1.8(2.6)$ & 0.97 \\
\hline First Hour Lactate $(\mathrm{mmol} / \mathrm{l})^{* *}$ & $1.8(1.5)$ & $1.7(2.6)$ & 0.94 \\
\hline Second Hour Lactate $\left(\mathrm{mmol} / \mathrm{l}^{* *}\right.$ & $2.0(1.7)$ & $2.0(2.6)$ & 0.98 \\
\hline Third Hour Lactate $(\mathrm{mmol} / \mathrm{l})^{* *}$ & $1.9(1.7)$ & $1.8(1.9)$ & 0.97 \\
\hline Fourth Hour Lactate $\left(\mathrm{mmol} / \mathrm{l}^{* *}\right.$ & $2.1(2.2)$ & $2.1(2.2)$ & 0.67 \\
\hline Fifth Hour Lactate $(\mathrm{mmol} / \mathrm{l})^{* *}$ & $2.1(2.9)$ & $2.0(1.9)$ & 0.74 \\
\hline Sixth Hour Lactate $(\mathrm{mmol} / \mathrm{l})^{* *}$ & $2.2(2.3)$ & $2.6(2.6)$ & 0.87 \\
\hline
\end{tabular}

Note: * Values are mean (standard deviation), ** Values are median (interquartile range)

The mean dose of GTN administered in the low dose group was 25 micrograms compared to 1506 micrograms in the higher dose GTN group. The authors felt this overall minimal dose was unlikely to contribute to any significant vasodilator effect, however it cannot be fully excluded.

One limitation of our study relates to the notable side effects of GTN. Venodilation with GTN has been associated with a higher fluid requirement during surgery to maintain intravascular volume and cardiac output [13, 23]. We did not however, look at morbidity in the ICU setting outside of early lactate trend and time to extubation. Time to extubation between both groups was comparable, but respiratory complications post operatively were not recorded.

One interesting study that showed promise by Kumar et al., looked at propofol vs GTN on the efficacy of rewarming along with extra volume added during $\mathrm{CPB}$ [14]. This study showed a benefit of propofol over GTN in reducing the afterdrop phenomenon, albeit the numbers were much smaller with only 10 patients in each $\mathrm{arm}$. This is one area that may have potential if investigated on a larger scale.

\section{Conclusion}

The authors demonstrated in this study that a higher dose GTN infusion during rewarming on CPB does not improve peripheral-core temperature gradient post operatively, and has no effect on post-operative lactate concentrations. Time to extubation was also unaffected.

\section{Abbreviations}

GTN: Glyceryl trinitrate; CPB: Cardiopulmonary Bypass; ICU: Intensive Care Unit; TIVA: Total Intravenous Anesthesia; BMI: Body Mass Index;

ASA: American Society of Anesthesiologists; ABG: Arterial Blood Gas; CVP: Central Venous Pressure; ACT: Activated Clotting Time; MAP: Mean Arterial Pressure

\section{Acknowledgements}

Intensive Care Unit Physicians and Nurses in Mater Misericordiae Hospital.

\section{Authors' contributions}

$\mathrm{DM}, \mathrm{ML}, \mathrm{MG}$ and GF made substantial contributions to the design of the research trial. $\mathrm{DM}, \mathrm{ML}, \mathrm{CH}, \mathrm{TW}$ and $\mathrm{IB}$ all made substantial contributions in collecting data. All authors approved submitted manuscript.

\section{Funding}

There was no external funding provided for this study.

\section{Availability of data and materials}

All data generated or analysed during this study are included in this published article [and its supplementary information files.

\section{Ethics approval and consent to participate}

Our study was approved by the Mater Hospital Research \& Ethics Committee (Ref 1/378/1869). All 82 patients consented for participation in the study.

\section{Consent for publication}

All patients consented for study results to be published.

\section{Competing interests}

There are no competing interests.

Received: 15 May 2020 Accepted: 28 July 2020

Published online: 10 August 2020

\section{References}

1. Ja G. Application of a mechanical heart and lung apparatus to cardiac surgery. Minn Med. 1954;37:171.

2. Zimmer HG. Perfusion of isolated organs and the first heart-lung machine. Can J Cardiol. 2001;17(9):963. 
3. Christenson JT, Schmuziger M, Maurice J, Simonet F, Velebit V. Gastrointestinal complications after coronary artery bypass grafting. J Thorac Cardiovasc Surg. 1994;108(5):899-906.

4. Turnbull KW, Mlyagishima RT, Gerein AN. Pulmonary complications and cardiopulmonary bypass: a clinical study in adults. Can Anaesth Soc J. 1974; 21(2):181-94.

5. Mandak J, Pojar M, Cibicek N, Lonsky V, Palicka V, Kakrdova D, Nedvidkova J, Kubicek J, Zivny P. Impact of cardiopulmonary bypass on peripheral tissue metabolism and microvascular blood flow. Perfusion. 2008;23(6):339-46.

6. Rees K, Beranek-Stanley M, Burke M, Ebrahim S. Hypothermia to reduce neurological damage following coronary artery bypass surgery. Cochrane Database Syst Rev. 2001;1:CD002138.

7. De Backer D, Dubois MJ, Schmartz D, Koch M, Ducart A, Barvais L, Vincent JL. Microcirculatory alterations in cardiac surgery: effects of cardiopulmonary bypass and anesthesia. Ann Thorac Surg. 2009;88(5):1396-403.

8. El-Rahmany HK, Frank SM, Vannier CA, Schneider G, Okasha AS, Bulcao CF. Determinants of core temperature at the time of admission to intensive care following cardiac surgery. J Clin Anesth. 2000;12(3):177-83.

9. Shinde SB, Golam KK, Kumar P, Patil ND. Blood lactate levels during cardiopulmonary bypass for valvular heart surgery. Ann Card Anaesth. 2005; 8(1):39.

10. Deakin CD, Petley GW, Smith D. Pharmacological vasodilatation improves efficiency of rewarming from hypothermic cardiopulmonary bypass. Br J Anaesth. 1998:81(2):147-51.

11. Flaherty JT. Role of nitrates in acute myocardial infarction. Am J Cardiol. 1992:70(8):B73-81.

12. Abrams J. Beneficial actions of nitrates in cardiovascular disease. Am J Cardiol. 1996;77:31C-7C.

13. Tai YH, Chang KY, Liao SW, Chung KC, Shih CC, Ho ST, Lu CC, Tsou MY. Intravenous loading of nitroglycerin during rewarming of cardiopulmonary bypass improves metabolic homeostasis in cardiac surgery: a retrospective analysis. J Anesth. 2016;30(5):779-88.

14. Kumar B, Chauhan P, Thinganam KS. Comparative effects of propofol and nitroglycerine on efficacy of rewarming in patients undergoing on-pump coronary artery bypass grafting. Ann Card Anaesth. 2015;18(2):145

15. Wall T, Heaney A, O'Flynn J, Flood G. Low dose glyceryl trinitrate during cardiopulmonary bypass rewarming reduces early postoperative serum lactate: a prospective observational study. Anaesthesia. 2017;72:74 111 RIVER ST, HOBOKEN 07030-5774, NJ USA: WILEY.

16. Schulz KF, Altman DG, Moher D. CONSORT 2010 statement: updated guidelines for reporting parallel group randomised trials. BMJ. 2010;340: C332. vitro only. No direct experiments on animals.

17. Demers P, Elkouri S, Martineau R, Couturier A, Cartier R. Outcome with high blood lactate levels during cardiopulmonary bypass in adult cardiac operation. Ann Thorac Surg. 2000;70(6):2082-6.

18. Andersen LW, Holmberg MJ, Doherty M, Khabbaz K, Lerner A, Berg KM, Donnino MW. Postoperative lactate levels and hospital length of stay after cardiac surgery. J Cardiothorac Vasc Anesth. 2015:29(6):1454-60

19. Svenmarker $\mathbf{S}$, Häggmark $\mathrm{S}$, Östman M. What is a normal lactate level during cardiopulmonary bypass? Scand Cardiovasc J. 2006;40(5):305-11.

20. Kogan A, Preisman S, Bar A, Sternik L, Lavee J, Malachy A, Spiegelstein D, Berkenstadt H, Raanani E. The impact of hyperlactatemia on postoperative outcome after adult cardiac surgery. J Anesth. 2012;26(2):174-8.

21. Lopez-Delgado JC, Esteve F, Javierre C, Torrado H, Rodriguez-Castro D, Carrio ML, Farrero E, Skaltsa K, Mañez R, Ventura JL. Evaluation of serial arterial lactate levels as a predictor of hospital and long-term mortality in patients after cardiac surgery. J Cardiothorac Vasc Anesth. 2015;29(6):1441-53.

22. Ranucci M, De Toffol B, Isgrò G, Romitti F, Conti D, Vicentini M. Hyperlactatemia during cardiopulmonary bypass: determinants and impact on postoperative outcome. Crit Care. 2006;10(6):R167.

23. Hynynen M, Palojoki R, Salmenperä M, Tikkanen I, Harjula A, Fyhrquist F, Heinonen J. Vasodilator properties of atrial natriuretic factor: a comparison with nitroglycerin, nitroprusside, and phentolamine during cardiopulmonary bypass. J Cardiothorac Anesth. 1989;3(6):720-5.

\section{Publisher's Note}

Springer Nature remains neutral with regard to jurisdictional claims in published maps and institutional affiliations.

Ready to submit your research? Choose BMC and benefit from:

- fast, convenient online submission

- thorough peer review by experienced researchers in your field

- rapid publication on acceptance

- support for research data, including large and complex data types

- gold Open Access which fosters wider collaboration and increased citations

- maximum visibility for your research: over $100 \mathrm{M}$ website views per year

At BMC, research is always in progress.

Learn more biomedcentral.com/submissions 